1 Universidade Federal do Rio Grande do Sul (UFRGS), Programa de Pós-Graduação em Administração (PPGA) Porto Alegre (RS), Brasil. Orcid: https://orcid. org/0000-0003-25816586

costa.rodrigoprado@gmail. com

2 Universidade Federal do Rio Grande do Sul (UFRGS), Programa de Pós-Graduação em Administração (PPGA) Porto Alegre (RS), Brasil. Orcid: https://orcid. org/0000-0003-20205882

maria.ceci@ufrgs.br

3 Universidade Federal do Rio Grande do Sul (UFRGS), Programa de Pós-Graduação em Administração (PPGA) Porto Alegre (RS), Brasil. Orcid: https://orcid org/0000-0002-19778424

paulo.abdala@ufrgs.br

\section{Do dilema preventivista ao dilema promocionista: retomando a contribuição de Sérgio Arouca}

\author{
From preventivist dilemma to promotionist dilemma: resuming the \\ contribution of Sérgio Arouca
}

Rodrigo Prado da Costa', Maria Ceci Misoczky², Paulo Ricardo Zilio Abdala ${ }^{\mathbf{3}}$

DOI: 10.1590/0103-1104201811916

RESUMO O objetivo deste trabalho é retomar a categoria 'dilema preventivista', cunhada por Sérgio Arouca em sua tese de doutorado, escrita em 1975, para refletir sobre sua atualização. Na tese, Arouca buscou compreender como foram produzidas as regras da formação discursiva da medicina preventiva e as relações com instâncias não discursivas, estudando as articulações com o modo de produção capitalista. A análise dessas articulações possibilitou a Arouca evidenciar que a medicina preventiva não fugiu à contradição fundamental da medicina que transforma a saúde - um valor de uso - em valor de troca, através do cuidado médico. Portanto, a busca que se faz ao resgatar essa categoria se orienta para uma pergunta própria: como aconteceu a atualização do discurso da medicina preventiva para o da promoção da saúde? A categoria cunhada por Arouca permitiu evidenciar que a promoção da saúde não foge à contradição fundamental da medicina e, ao invés de ser uma inovação para o campo da saúde, é uma atualização do discurso preventivista, configurando, assim, o dilema promocionista.

PALAVRAS-CHAVE Medicina preventiva. Promoção da saúde. Atenção Primária à Saúde.

\begin{abstract}
The aim of this study is to resume the category 'preventivist dilemma', coined by Sérgio Arouca in his doctoral thesis, written in 1975, to reflect on its updating. In his thesis, Arouca sought to understand how the rules of discursive formation of preventive medicine and relations with non-discursive instances were produced, studying the articulations with the capitalist mode of production. The analysis of these articulations enabled Arouca to evidence that preventive medicine did not escape the fundamental contradiction of medicine that transforms health - a usevalue into exchange-value through medical care. Therefore, the research that is done by rescuing that category is directed to a specific question: how did the update of the discourse of preventive medicine for health promotion happened? The category coined by Arouca has made it possible to highlight that health promotion does not escape the fundamental contradiction of medicine, and, instead of being an innovation for the field of health, it is an update of the preventivist discourse, setting, thus, the promotionist dilemma.
\end{abstract}

KEYWORDS Preventive medicine. Health promotion. Primary Health Care. 


\section{Introdução}

Na sua tese de doutorado, Sérgio Arouca examinou como foram produzidas as regras da formação discursiva da medicina preventiva e as relações com instâncias não discursivas, estudando as articulações com o modo de produção capitalista, a fim de compreender a simultaneidade e a contradição medicina preventiva-medicina curativa. Sobretudo, partiu do princípio de que o modo de exercer a medicina decorre de uma determinação histórico-social e, se a medicina preventiva tinha por projeto uma nova determinação, o estudo desse projeto corresponderia a conhecer as contradições da própria sociedade expressas em um campo específico de sua análise, a medicina. Para tanto, Arouca ${ }^{1}$ estudou o discurso preventivista através da metodologia arqueológica proposta por Foucault ${ }^{2}$, para uma aproximação com o materialismo histórico e a teoria do valor em Marx ${ }^{3}$.

Para o entendimento dessas contradições, Arouca ${ }^{1}$ abordou a estrutura social de emergência da medicina preventiva, defendendo que ela não se constituiu em um novo conhecimento a partir da higiene, mas como crítica à prática médica centrada na medicina curativa, correspondendo à singularidade de um determinado contexto histórico. $\mathrm{O}$ projeto da medicina preventiva definiu uma nova organização do conhecimento médico, que incluiu reformas nos currículos das faculdades de medicina e a criação de departamentos e cátedras de medicina preventiva. Esse processo teve como princípios as proposições de Leavell e Clark 4 , e o paradigma da História Natural das Doenças (HND).

Articulando cuidado médico e modo de produção capitalista, Arouca ${ }^{1}$ chegou à centralidade de sua tese, evidenciando a contradição fundamental da medicina: ter como objeto valores vitais - que, para os seres humanos, são valores de uso - transformados em valores de troca pela dinâmica do modo de produção capitalista. Essa apreensão possibilitou ao autor a construção da categoria 'dilema preventivista', evidenciando que a medicina preventiva não escapou à contradição da própria medicina. Portanto, mesmo apresentando-se como um projeto de mudança da prática médica, a introdução das medidas preventivistas ao cuidado médico ficou limitada a uma leitura liberal da medicina, constituindo-se, então, em um espaço conservador e funcional ao capitalismo.

A compreensão do dilema preventivista permite discutir a promoção da saúde, difundida contemporaneamente como uma importante estratégia para melhorar as condições de saúde da população por intermédio de um conjunto de prescrições normativas a respeito de 'hábitos saudáveis'. Ao analisar a promoção da saúde, denota-se que, como formação discursiva, ela surgiu no momento de ascensão do neoliberalismo. O conjunto das premissas neoliberais, somado aos custos da atenção médica e do enfoque clínico sob a responsabilidade dos profissionais médicos, fez com que a promoção da saúde aparecesse no cenário internacional como uma inovação para o campo da saúde. Tendo início no Canadá, na década de 1970, a partir do documento intitulado 'Informe Lalonde', a promoção da saúde logo foi incorporada à Atenção Primária à Saúde (APS) como principal estratégia da saúde, a partir da Conferência de Alma-Ata, na década de 1980. Em 1986, com a Carta de Ottawa, foram estabelecidas as principais estratégias da promoção da saúde, momento em que foram definidos seus conceitos estratégicos: determinantes sociais da saúde, fatores de risco e empowerment. Este conjunto de conceitos é até hoje amplamente divulgado, seja no espaço privado ou no espaço público. Entretanto, ao retomar a tese de Arouca', percebe-se que o conceito de promoção da saúde não é novo, visto que já aparecia no esquema desenvolvido por Leavell e Clark 4 , na década de 1940, compondo um dos níveis de prevenção da medicina preventiva.

Diante disso, a partir da compreensão da especificidade do trabalho de Arouca ${ }^{1}$, este artigo objetiva questionar o movimento da 
promoção da saúde em relação à sua articulação com a medicina e a sociedade. Sobretudo, a recuperação da categoria 'dilema preventivista' apoia a pergunta na qual se originou este trabalho: como aconteceu a atualização do discurso da medicina preventiva para o da promoção da saúde? Esse resgate permite evidenciar que a promoção da saúde, embora seja apresentada como uma inovação para o campo da saúde, na década de 1970, não é uma inovação em relação ao 'dilema preventivista', mas uma atualização de seu discurso, não escapando à contradição fundamental da medicina. Portanto, o dilema persiste, agora, sob uma nova roupagem, configurada sob o dilema promocionista.

\section{Métodos}

A compreensão do dilema preventivista desenvolvido na obra de Arouca ${ }^{1}$ levou a um questionamento sobre o movimento da promoção da saúde por compreender que ela ocupa um espaço análogo ao da medicina preventiva: o da prevenção das doenças, respeitadas suas singularidades. Ao analisar a promoção da saúde, denota-se que, como formação discursiva, ela surgiu em um contexto muito semelhante ao da medicina preventiva, conforme apontado por Arouca ${ }^{1}$ e caracterizado, principalmente, pela ascensão do neoliberalismo. Para concretizar este entendimento, adotou-se a lógica da interdiscursividade. Segundo Bakhtin 5 , o enunciado constitui um todo de sentido e, por isto, permite encontrar respostas. Qualquer texto tem um intertexto, parte de um contexto mais amplo e se constitui em um elo, em uma cadeia contínua e inesgotável de sentidos. Sendo assim, o sentido de um discurso só pode ser buscado no interdiscurso. Tendo esse entendimento, tomou-se a tese de Arouca ${ }^{1}$ como um elo que propicia entender os sentidos contemporâneos do movimento da promoção da saúde.

\section{Resultados}

\section{O dilema preventivista na tese de Sérgio Arouca}

$\mathrm{Na}$ introdução de sua tese, Arouca ${ }^{\mathbf{1}}$ deixou claro que, para compreender o significado da medicina preventiva, era necessário determinar a que tipo de racionalidade o conceito pertencia em um dado contexto social. Assim, tem-se sua pergunta central:

O que representa a emergência do discurso preventivista privilegiando uma 'nova atitude', reintroduzindo a quantificação e a formalização no saber clínico, colocando em questão a experiência pedagógica do hospital e relibertando a enfermidade para o espaço social? E, enfim, qual a novidade da institucionalização de um espaço que coloca em questão a própria medicina, ao mesmo tempo que se oferece como projeto alternativo? ${ }^{1(15)}$.

Como formação discursiva, a medicina preventiva emergiu em um campo formado por três vertentes: 1) a higiene, surgida no século XIX, ligada ao desenvolvimento do capitalismo e da ideologia liberal; 2) a discussão dos custos da atenção médica nos Estados Unidos, no período de 1930 a 1940, diante de uma crise internacional e da ameaça de uma intervenção estatal com a respectiva reação das organizações médicas; e 3) a redefinição das responsabilidades médicas surgidas no interior da educação médica.

Diante disso, Arouca ${ }^{1}$ apontou que entre 1950 e 1953 houve um marco importante na redefinição dos objetivos do ensino médico, realizados pelo Comitê de Educação Médica da Associação Americana de Medicina em conjunto com a Associação Americana de Colégios Médicos, que elaboraram uma declaração que introduziu alguns dos principais preceitos da medicina preventiva, servindo como base à Conferência de Colorado Springs (1953), local de emergência do discurso preventivista. 
Conforme Arouca' ${ }^{1}$ o campo teórico das conceituações a respeito da medicina preventiva definiu, pelas regularidades discursivas, três principais premissas da nova conduta: 1) enfoque no indivíduo e na família; 2) incorporação na prática diária do médico, independentemente de sua especialidade; e 3) nova atitude por parte do profissional médico.

Arouca $^{1}$ definiu esse processo como um movimento que, em um primeiro momento, faz a crítica da medicina curativa, para, em um segundo momento, defender seu próprio projeto. A medicina curativa era uma prática médica que se esgotava no diagnóstico e na intervenção terapêutica, privilegiando a doença; a prevenção e a reabilitação eram secundárias. Ou seja, tratou de demonstrar a ineficiência dessa prática, devido ao enfoque médico predominantemente biológico, da especialização crescente da medicina e da desvinculação dos reais problemas de saúde da população.

Os princípios teóricos da medicina preventiva foram introduzidos, principalmente, por Leavell e Clark4, que tiveram influência na divulgação das ideias e na implantação dos departamentos de medicina preventiva nos Estados Unidos, que mais tarde seriam expandidos para todos os países. Os princípios e condutas da nova disciplina deveriam dar conta do desdobramento do conhecimento em diversas áreas, especialidades e subespecialidades, tendo como proposta de reorganização e síntese desse movimento a HND. Para esses autores ${ }^{4(25)}$, a medicina preventiva é

a ciência e a arte de prevenir a doença, prolongar a vida e promover a saúde física, mental e a eficiência, para interceptar a história natural da doença em qualquer estágio de sua evolução.

A HND é a inter-relação entre agente, hospedeiro e ambiente, e está dividida em dois períodos: o primeiro, a pré-patogênese; e o segundo, a patogênese. Na pré-patogênese, momento em que a doença não se iniciou, devem ser estabelecidas medidas de prevenção primária contra os agentes patológicos, através da promoção da saúde, a fim de estabelecer como ótima a saúde nos seres humanos. $\mathrm{Na}$ patogênese, quando a doença está manifestada, são aplicadas medidas de prevenção secundária e terciária, através do diagnóstico clínico, tratamento e reabilitação.

Nessa proposição, a relação médico-paciente deixaria de ser ocasional, cabendo às condutas preventivas a manutenção do equilíbrio da vida. Assim, o cuidado à saúde se transforma em prática cotidiana, em ponto de articulação da totalidade criada com o campo médico. Portanto, como projeto, a medicina preventiva promoveu uma reorganização do discurso médico, proclamando uma nova atitude na prática médica, que deveria ser implantada através da educação médica.

Para analisar o projeto da medicina preventiva, Arouca ${ }^{1}$ retomou seus conceitos estratégicos: integração; inculcação e resistência; mudança; e esquema evolutivo. Em seguida, analisou suas regras da formação discursiva, a fim de compreender as condições concretas da existência dos elementos que compõe o discurso preventivista em sua singularidade, constatando que este construiu, diante da medicina, um projeto que lhe era, simultaneamente, igual e diferente. Ou seja, tratava-se de um discurso que falava de uma medicina adjetivada que se tornaria o próprio futuro da medicina, aparecendo como projeto e como processo de transformação. Ao assumir essa relação de identidade e de mudança da medicina, o discurso preventivista tomou como seus objetos a saúde e a doença, a prática e a educação médica.

Dessa forma, tornou-se, ao mesmo tempo, alternativo e afirmativo. Instaurou-se através da institucionalização de espaços discursivos, através dos departamentos de medicina preventiva, das associações nacionais de escolas médicas e de diferentes instituições internacionais.

Após estudar as condições de emergência e as regras de formação discursiva da medicina preventiva, Arouca ${ }^{1}$ analisou a articulação da medicina com a sociedade, a fim de apanhar, 
em sua totalidade, a especificidade da medicina preventiva, momento em que faz uma aproximação teórica com a teoria de valor de Marx ${ }^{3}$.

Ao analisar a articulação da medicina com a sociedade, Arouca ${ }^{1}$ partiu da unidade mais simples: o cuidado médico. O cuidado é o próprio processo de trabalho de agentes investidos e legitimados socialmente nesta função, monopolizando o exercício e o conhecimento de tal atividade. O cuidado é composto pela corporificação de instrumentos e condutas técnicas em uma relação social específica, satisfazendo necessidades humanas nos modos de andar a vida. Ele apresenta uma dupla característica: é um processo de trabalho, tendo como objetivo a intervenção sobre valores vitais (biológicos e psicológicos); é unidade de troca por atender necessidades humanas, tendo atribuído, social e historicamente, um valor.

Neste processo, o que se consome é o próprio cuidado, ou seja, o próprio trabalho e não o produto deste trabalho, em outras palavras, 0 resultado do cuidado é a intervenção (normativa ou transformadora) sobre valores vitais, cujo consumo é realizado na própria vida, no seu uso e no consumo da força de trabalho no processo produtivo, sendo, portanto, consumido no cuidado o trabalho de seus agentes e seus instrumentos, e não o seu resultado'(205).

Dessa relação, Arouca ${ }^{1}$ evidenciou as características básicas do cuidado médico: é uma unidade de produção e consumo; implica em três valores: seu próprio valor como unidade de troca, os valores vitais que toma como objetos, e os valores de uso e de troca atribuídos socialmente aos valores vitais; é um processo de trabalho que envolve conhecimentos, técnicas, relações sociais e necessidades a serem satisfeitas; é determinado pelas necessidades vitais nos mais variados modos de andar a vida e determina socialmente as necessidades e seu espaço de coberturas.

Essas características definem o espaço no qual se encontra a contradição fundamental da medicina ${ }^{1}$. Ela atua nas margens entre o vital e o social, uma vez que define como seu objeto o vital, que é influenciado pelo social, encontrando, nesse lugar, seus limites e suas possibilidades.

O produto da prática médica, o cuidado, refere-se a valores que, para seus possuidores, existem como valores de uso, ou seja, refere-se à própria vida dos seres humanos. Quando uma pessoa, por exemplo, está com um problema de saúde, ela procura o cuidado médico para retomar sua condição de saúde e seguir seu modo de andar a vida. Então, na relação entre essa pessoa e o médico, há uma dependência entre a necessidade do cuidado e o saber que somente o médico possui para proporcionar àquela as condições necessárias de sua recuperação. Nesta relação, o valor de uso aparece como a própria recuperação da saúde, para que a pessoa possa deixar a condição de estar doente. Todavia, sanar o problema dessa pessoa implica para ela não só uma melhora de sua condição de saúde, mas, também, a possibilidade de retomar as condições necessárias para exercer sua força de trabalho, pois, como trabalhador, depende disso para sua sobrevivência no modo de produção capitalista. Porém, no momento em que a saúde, como valor biológico, passa a ser considerada também como um atributo da força de trabalho, para que melhor seja consumida no processo produtivo, ela, como valor de uso para seu detentor, passa a ser um valor de troca, a partir da venda de sua força de trabalho no mercado. Portanto, se inicialmente a saúde tem como significado um valor de uso para seu detentor, imediatamente ela é transformada em valor de troca para a sua própria sobrevivência.

Essa é a contradição fundamental da medicina: ter como objeto valores vitais que, para os seres humanos, são valores de uso no processo da vida, transformados em valores de troca pela dinâmica do modo de produção capitalista. A vida, então, é tratada como mercadoria, tendo no cuidado médico a forma para que sejam mantidas as condições necessárias de manutenção da saúde utilizada como valor de 
troca no mercado. O uso atribuído a valores vitais determina, também, quais deles devem ser tomados prioritariamente como objetos de trabalho da medicina, fazendo com que se crie uma normatividade destes valores em termos de doenças e cabendo a ela o cuidado dessas alterações $\mathbf{1}$.

Entretanto, segundo Arouca', a mesma atividade médica que faz a manutenção e recuperação do valor de uso de uma pessoa, que, ao vender sua força de trabalho passa a significar a manutenção de valor de troca, funciona, para as classes hegemônicas, como um valor de uso, que é colocado como corporificação do capital no processo de extração de mais-valia.

Conforme Arouca ${ }^{1}$, o cuidado médico contribui para o aumento da produtividade quando os trabalhadores são mantidos em boas condições de saúde, direta ou indiretamente, devido à diminuição do absenteísmo e de acidentes de trabalho. Pode, também, contribuir para a mais-valia absoluta, quando mantém o trabalhador em condições boas de saúde, possibilitando, desta forma, a realização de jornadas extraordinárias de trabalho.

Em síntese, podemos dizer que a saúde, como valor biológico, pode ser considerada como um atributo da força de trabalho para que ela melhor possa ser consumida no processo produtivo. Porém, paradoxalmente, a força de trabalho como mercadoria incorpora para a sua manutenção um quantum de trabalho cujo efeito não é aumentar o seu valor, mas, sim, possibilitar o aumento da sua exploração'(219).

A articulação da medicina está referida à manutenção, à recuperação e à reprodução da força de trabalho tomada como um valor de troca para o proletário, funcionando como um valor de uso para as classes hegemônicas, a partir da exploração do trabalhador. O trabalho médico se tornou funcional a essa reprodução dentro da lógica capitalista, sendo diretamente produtivo quando possibilita um acréscimo na mais-valia. A medicina preventiva aparece nesse campo de tensões da medicina como um projeto que se apresenta como alternativa de solução ao conjunto de problemas das formações sociais relativas à incidência de doenças e abrangência dos cuidados médicos, centralizando no profissional médico um novo comportamento. Contudo, o fez a partir de uma leitura liberal, mantendo a natureza do cuidado médico, sem que escapasse à contradição da medicina.

Assim, a incorporação das atitudes preventivistas ficou diretamente ligada ao aumento da produtividade do trabalho.

Não foi por mero acaso que as chamadas empresas médicas adotaram rapidamente, após a sua criação, o discurso preventivista na justificativa de sua validade ${ }^{\mathbf{1 ( 2 1 3 )}}$.

Na política estatal, também foram incorporadas, por meio de organismos da saúde pública, as atitudes preventivistas, visando, principalmente, cobrir a atenção das populações ditas marginais.

Portanto, a apreensão da contradição fundamental da medicina possibilitou à Arouca ${ }^{1} \mathrm{a}$ construção da categoria 'dilema preventivista', pois, mesmo a medicina preventiva tendo se apresentado como um novo projeto, como um movimento de mudança, ela manteve a mesma lógica do cuidado médico, constituindo-se em um espaço conservador e funcional ao capitalismo. Na dimensão do ensino, a medicina preventiva é mais uma disciplina-tampão, entre as tantas que criticam a disciplina dentro da qual nascem, centram suas estratégias de modificação da prática no ensino, possuem organização institucional legitimada e se constituem em discursos e práticas concretas que contribuem para a estabilização ideológica de propósitos mais gerais e idealistas ${ }^{1}$.

Feita essa breve apresentação, podem ser tratadas as mudanças sociais e práticas de saúde que possibilitaram à medicina preventiva, como uma medicina de orientação liberal e individualista, se transformar na promoção da saúde, hoje amplamente divulgada e defendida no âmbito nacional e internacional. 


\section{A promoção da saúde}

A promoção da saúde, como formação discursiva, emergiu em um contexto muito semelhante ao apontado na análise de Arouca ${ }^{1}$, em relação à medicina preventiva: um momento de crise econômica. Dessa vez, com o neoliberalismo como estratégia ofensiva do capital.

O neoliberalismo é um projeto econômico-político de classe (capitalista) expresso através de uma estratégia de acumulação do capital, que se baseia especificamente na subordinação e sujeição absoluta ao mercado como dispositivo de produção e reprodução social em sentido amplo ${ }^{6}$. Um dos conceitos mais significativos do ideário neoliberal é a mudança de enfoque do homo economicus (homem econômico) tido como princípio antropológico da corrente anglo-americana - para o de homo redemptoris (homem empresário/empreendedor), da corrente austríaca ${ }^{7}$. Conforme Puello-Socarrás ${ }^{7}$, o conceito de homem empresário/empreendedor, antes de ser uma premissa dos tempos atuais, é uma ideia historicamente arraigada no pensamento liberal, na qual o conceito de homem econômico era uma categoria que interpretava dedutivamente o ser humano como um agente econômico racional e um indivíduo eminentemente calculador. Entretanto, a partir do século XX, esse conceito passa a fazer parte de uma reivindicação do empreendedorismo como exigência para a compreensão do ser humano diante das condições econômicas do mercado, ou seja, frente ao capital financeiro e à governança corporativa, entre outros. Neste contexto, o homem empreendedor é um homem econômico, mas não no sentido puro como defendia o neoclassicismo anglo-americano, pois ele é um empresário de si mesmo, aprofundando o individualismo típico do neoliberalismo.

A consolidação da doutrina neoliberal, em nível global, foi caracterizada pelo 'Consenso de Washington' em sua versão original, de 1989 (CW-89), e de suas adaptações posteriores (Consenso Revisado, Ampliado e PósWashington), realizadas pelos organismos multilaterais de crédito subordinados aos interesses de Washington (Estados Unidos), como o Fundo Monetário Internacional (FMI), o Banco Mundial (BM) e o Banco Interamericano de Desenvolvimento (BID). Essas adaptações ao consenso original emergiram quase uma década depois como resposta das agências internacionais a um conjunto de progressivas resistências sociais antineoliberais e constantes políticas contra-hegemônicas, principalmente na América Latina e no Caribe, no plano sociopolítico e eleitoral, motivados pela catástrofe da hegemonia liberal, especificamente em termos sociais ${ }^{8}$. Sem abrir mão dos postulados macroeconômicos, o neoliberalismo se viu obrigado a adaptar, às suas práticas políticas, a inclusão de temas sociais para manter sua posição central de poder e seus postulados. Temas como pobreza e inclusão social, bem como a presença estatal (reguladora) e o reconhecimento de falhas do mercado, passaram a fazer parte das diretrizes sistematicamente incorporadas na agenda neoliberal das agências multilaterais, sem abrir mão da essência do projeto de sujeição e subordinação ao mercado. Além disso, temas como justiça social, equidade e empoderamento, entre outros, passaram a fazer parte das prescrições da agenda neoliberal no conjunto de políticas sociais ${ }^{8}$.

Obviamente, a atenção à saúde não poderia ficar fora desse processo. Incorporando as premissas do ideário neoliberal, a APS surge como resposta, em um primeiro momento, à crise dos anos 1970 e à discussão dos elevados custos da atenção médica, para firmar-se como uma nova perspectiva, tendo a promoção da saúde como sua principal estratégia. Conforme Vasconcelos e Schmaller', os elevados custos da saúde estavam relacionados à dependência ao modelo biomédico, centrado em uma abordagem fisiopatológica individual de diagnóstico e terapêutica. Nesse modelo de atenção à saúde, o núcleo central preconizava a unidade hospitalar para tratamento, bem como elevados aparatos tecnológicos e o suporte de especialistas. 
A discussão em torno da necessidade de uma nova abordagem para o campo da saúde, somada à crise econômica da década de 1970 e ao consequente avanço do neoliberalismo, fez com que o processo de mudança ocorresse de forma acelerada. Isso deu início a uma série de encontros de países do centro capitalista e de organizações internacionais para a formulação de uma nova perspectiva que correspondesse às exigências do campo econômico, ou seja, da contenção dos elevados custos sociais.

Devido à crise fiscal, ao elevado custo em tecnologias médicas e ao modelo biomédico, o Canadá foi um dos países que, naquele momento, fez uma forte crítica ao seu sistema de saúde, resultando na apresentação, em maio de 1974, do documento 'A new perspective on the health of Canadians'10, também conhecido como 'Informe Lalonde'. Foi a primeira vez que o termo promoção da saúde apareceu oficialmente em um documento como parte de um pensamento estratégico para reorganizar a atenção à saúde.

As premissas do 'Informe Lalonde' foram definidas no item denominado 'campo da saúde', reunindo os 'determinantes da saúde', conceito que contempla os quatro componentes que influenciam a saúde ${ }^{10}$ : biologia humana, ambiente, estilo de vida e organização da assistência à saúde. Destes componentes, decorrem cinco estratégias: promoção da saúde, regulação, eficiência da assistência médica, pesquisa e fixação de objetivos. No documento, a promoção da saúde teve como definição "informar, influenciar e assistir pessoas e organizações, para que assumam maiores responsabilidades e sejam mais ativos em matéria de saúde"10(66). O enfoque da estratégia da promoção da saúde foi, essencialmente, voltado aos estilos de vida, englobando, por exemplo, a alimentação, o tabaco, o álcool, as condutas sexuais e o uso de drogas, e evidenciando, para tanto, a necessidade de responsabilização individual sobre a própria saúde. Assim, ao propor a retirada do enfoque da assistência médica sob os cuidados exclusivos do profissional médico, Lalonde ${ }^{10}$ introduziu a concepção de que as pessoas deveriam se responsabilizar sobre seu próprio cuidado com a saúde, pois suas atitudes resultariam na expressão de sua saúde.

Paralelamente à reestruturação que vinha ocorrendo no Canadá em torno da promoção da saúde, a Organização Mundial da Saúde (OMS) fomentou, na década de 1970, um amplo debate em torno de alternativas viáveis para a extensão dos cuidados à saúde nos países, de forma a atender as expectativas do cenário econômico. O ponto culminante foi a Conferência Internacional de APS, realizada em 1978, em Alma-Ata, no Cazaquistão, em parceria com o Fundo das Nações Unidas para a Infância (Unicef) ${ }^{11}$. Dois documentos resultaram da conferência. Na Declaração ${ }^{12}$, a promoção da saúde apareceu como um conceito essencial, acompanhada dos conceitos de prevenção, tratamento e reabilitação.

Analisando os documentos da conferência e as declarações posteriores sobre a APS, denota-se que o conjunto de afirmações e recomendações demonstrou uma preocupação com a necessidade de implantar uma reforma estrutural de cunho socioeconômico nos países - principalmente, nos subdesenvolvidos - como perspectiva de superação das barreiras econômicas presentes naquele momento. A proposta da APS, para além da implantação de um conjunto de diretrizes em saúde, fez parte do conjunto de reformas do aparelho de Estado ao indicar a necessidade de reestruturação interna dos países, conforme preconizado pelo neoliberalismo. Essa postura, presente na conferência, é reafirmada nas Recomendações de Alma-Ata, quando se dá a publicação do documento intitulado 'Saúde para Todos no Ano 2000', que propunha ajustes no campo da saúde em longo prazo, além do acompanhamento constante das reformas preconizadas em Alma-Ata ${ }^{13}$.

Em novembro de 1986, em Ottawa, ocorreu a I Conferência Internacional sobre Promoção da Saúde. Tendo a participação de 35 países, e resultando na Carta de Ottawa, ainda é considerada a principal conferência sobre promoção da saúde por ter se tornado uma 
referência para o campo, em todo o mundo ${ }^{13}$. Segundo Labonte ${ }^{\mathbf{1 4}}$, a Carta de Ottawa afirmou, sobretudo, que a promoção da saúde demarcou uma inovação, ao introduzir um conjunto de preceitos que antes não eram trabalhados no cuidado à saúde.

A promoção da saúde deveria, então, dar conta de um conjunto de valores: solidariedade, equidade, democracia, cidadania, desenvolvimento, participação e ação conjunta. Daí decorrem as principais estratégias: políticas públicas saudáveis; ambientes favoráveis à saúde; reorientação dos serviços de saúde; reforço da ação comunitária; e desenvolvimento de habilidades pessoais ${ }^{15}$. Além de seus conceitos estratégicos: os determinantes sociais da saúde, os fatores de risco e o empowerment.

Segundo Zioni e Westphal ${ }^{16}$, os determinantes sociais estão condicionados ao contexto estrutural socioeconômico e político da sociedade, que, por sua vez, pode ser traduzido como uma estratificação social, definida em termos de excedente econômico. Esta estratificação leva ao que seriam os determinantes sociais da saúde expressos pela distribuição desigual de três tipos de fatores: materiais, como habitação, alimentação, trabalho etc.; psicossociais e comportamentais; e biológicos. Estes fatores representam os níveis de saúde em cada sociedade, conforme seu desenvolvimento. Entretanto, nesta concepção, os fatores causais dos problemas de saúde aparecem puramente no plano empírico e, para minimizar a determinação social, defende-se a necessidade de uma maior atuação sobre os fatores de risco, sem que se transformem efetivamente as condições sociais? ${ }^{9}$.

A epidemiologia trata o risco como a probabilidade de um conjunto de membros de uma população desenvolver uma doença ou algum evento relacionado à saúde, surgindo, então, a noção correlata de fator de risco, que pode ser definido como o atributo de um grupo de pessoas que apresentam uma determinada patologia com maior incidência do que os demais grupos populacionais, oferecendo, assim, um forte risco à saúde de todos ${ }^{17}$. Desta forma, prever os fatores de risco significa minimizar problemas futuros. Na promoção da saúde, esta concepção é utilizada na estruturação de ações e estratégias como as Políticas Públicas Saudáveis, que têm como concepção contribuir para a escolha de hábitos de vida saudáveis ${ }^{16}$.

O controle sobre os determinantes sociais e os fatores de risco no processo saúde-doença, por parte dos indivíduos, encontra-se na principal estratégia da promoção da saúde, através do conceito de empoderamento e suas variantes: o psicológico e a comunidade.

O empoderamento psicológico enfatiza uma perspectiva filosófica individualista, que tende a ignorar a influência dos fatores sociais e estruturais, desconectando o comportamento dos seres humanos do contexto sociopolítico em que estão inseridos. A centralidade desta perspectiva consiste na regulação da vida por parte de políticas e práticas macrossociais, fazendo com que as pessoas se responsabilizem cada vez mais por sua condição de vida $^{\mathbf{1 8}}$. A perspectiva centrada na comunidade compreende que existem níveis diferenciados de poder distribuídos de forma desigual na sociedade, o que justificaria as disparidades sociais. A responsabilização individual não é criticada, mas ampliada para as comunidades, de forma que a responsabilização coletiva é apontada como alternativa de fortalecimento da crítica à macroestrutura.

Assim, o discurso do fortalecimento das comunidades e dos indivíduos através do empoderamento retira a responsabilidade do Estado de prover um sistema de saúde adequado, por meio da transferência de responsabilidades, a cada indivíduo, sobre sua condição de vida. Nesse sentido, embora haja problemas macroestruturais reconhecidos, os indivíduos é que são os responsáveis por mudá-los. Essa estratégia centrada no empoderamento nada mais é do que a prescrição neoliberal do enfoque no indivíduo, que se justifica na concepção de que todo ser humano é um empresário/empreendedor, conforme apontado por Puello-Socarrás 7 . Logo, o conjunto normativo de prescrições da promoção 
da saúde se apresenta como sendo o próprio espaço de oportunidades preconizado pelo neoliberalismo, no qual os indivíduos encontram as oportunidades de melhorar sua condição de saúde, bastando, para isto, que se tornem agentes ativos por meio da responsabilização de cada aspecto de sua vida no que diz respeito a hábitos saudáveis. Ao prescrever o que é bom ou mau para a saúde de cada um, a promoção da saúde se estabelece como autoridade suprema sobre a própria existência humana, tendo na noção de fatores de risco o epicentro das normas de conduta que prescreve.

\section{Considerações finais: $o$ dilema promocionista}

O conceito de promoção da saúde já havia aparecido na década de 1940, quando Leavell e Clark ${ }^{4}$ o introduziram ao desenvolverem o modelo da HND, no período da pré-patogênese. O que o movimento da promoção da saúde iniciado na década de 1970 fez foi se ater ao nível da prevenção primária do modelo preconizado por Leavell e Clark ${ }^{4}$, negligenciando todo o resto, tratando de apresentar um esquema pedagógico baseado na causalidade de fatores simples e até mesmo em uma redução monocausal, centrado, exclusivamente nos fatores de risco, em cada aspecto da vida $^{19}$. Isso porque, nos demais níveis preconizados por Leavell e Clark ${ }^{4}$, o trabalho do médico era indispensável. Assim, como forma de contenção de custos da atenção médica, a promoção da saúde desloca a centralidade do trabalho médico para o nível da prevenção primária e, complementarmente, delega as responsabilidades de cuidado aos indivíduos.

Segundo Nogueira ${ }^{19(179)}$, a pregação de "hábitos saudáveis" sob a responsabilidade do indivíduo em cada aspecto de sua vida é um retorno à normalização imposta pela higiene no final do século XIX e começo do século XX, que deu origem à medicina preventiva e às suas normas. Desta forma, não deixa de ser um projeto similar de medicalização da totalidade da existência humana e não só da dimensão da doença; medicalização que dispensa a figura do médico, pois molda a cultura cientificista a seus propósitos, afetando diretamente o modo como as pessoas cuidam de sua saúde ${ }^{19} \mathrm{e}$, na expressão de Arouca ${ }^{1}$, seus modos de andar a vida. Daí, compreende-se que a promoção da saúde não se separou da medicina preventiva. De fato, o que se tem é uma atualização do discurso da medicina preventiva, dado o contexto histórico que exigiu essa reconfiguração. Devido à crise econômica e ao aumento dos custos da atenção médica, foi imposta uma reestruturação que correspondesse às exigências do ideário neoliberal. Além disto, importa destacar que não é mera coincidência que temas da agenda neoliberal como justiça social, equidade e empoderamento, entre outros, sejam os mesmos preconizados pela promoção da saúde.

Diante do exposto até aqui, se na medicina preventiva ficou evidente a existência do dilema preventivista ${ }^{1}$, a promoção da saúde não escapa ao dilema promocionista. Aqui reside a centralidade da tese de Arouca ${ }^{1}$ para este trabalho. Como a promoção da saúde é uma atualização do discurso da medicina preventiva, não há rompimento com a contradição fundamental da medicina, conforme foi demonstrado por Arouca' ${ }^{1}$. Ao contrário, a articulação da medicina com o modo de produção capitalista é fortalecida. A análise de Arouca ${ }^{1}$ demonstrou que, na relação centrada no médico-paciente, o cuidado médico contribui para a recuperação e manutenção da força de trabalho e, ao fazer isto, contribui para a perpetuação de tal relação de troca, sendo funcional ao modo de produção capitalista. Na promoção da saúde, o enfoque dos cuidados sob a responsabilidade do indivíduo não diminui essa contradição, ao contrário, ela a aprofunda, na medida em que as pessoas são convertidas em empresárias de si mesmas. O cuidado não depende, na promoção da saúde, apenas da figura médica, mas essencialmente, do indivíduo, sendo ele o responsável por sua 
saúde e, ao mesmo tempo, por sua condição social.

Sob o discurso da promoção da saúde, a medicalização é ampliada ao prescrever um conjunto de hábitos saudáveis aos indivíduos, mantendo, assim, a reprodução e manutenção da força de trabalho a ser consumida no processo produtivo.

Em última análise, a promoção da saúde é uma atualização da medicina preventiva, mantendo os preceitos que transformam um valor de uso, que é a saúde, em valor de troca, mediado por relações sociais subordinadas à lógica do mercado. Ao fazer isto, reforça a articulação da medicina com o modo de produção capitalista.

\section{Referências}

1. Arouca SAS. O dilema preventivista: contribuição para a compreensão e crítica da medicina preventiva [tese]. Campinas: Universidade Estadual de Campinas; $1975.261 \mathrm{p}$.

2. Foucault M. A Arqueologia do Saber. 7. ed. Rio de Janeiro: Forense Universitária; 2008.

3. Marx K. O capital: crítica da economia política. São Paulo: Boitempo; 2013.

4. Leavell HEG, Clark G. Medicina Preventiva. Rio de Janeiro: Mcgraw-Hill; 1976.

\section{Colaboradores}

Misoczky MC contribuiu para a concepção do estudo, elaboração de versão preliminar e aprovação final da versão a ser publicada. Abdala PRZ contribuiu para a concepção do trabalho, avaliação crítica da primeira versão do trabalho em termos da resolução de problemas de precisão e integridade do texto, revisão criteriosa do conteúdo intelectual do artigo, aprovação e revisão da versão final para publicação. Costa RP contribuiu para a concepção do trabalho, coleta dos dados bibliográficos para a elaboração do texto, interpretação dos dados e redação, aprovação e revisão da versão final do artigo.
5. Bakhtin M. La poétique de Dostoievski. Paris: Seul; 1970.

6. Puello-Socarrás JF. Ocho tesis sobre el neoliberalismo (1973-2013). Revista Espacio Critico [internet]. 2013 [acesso em 2017 nov 5]; 1:167-186. Disponível em: http://www.espaciocritico.com/sites/all/files/ revista/recrt18/n18_a01.pdf.

7. Puello-Socarrás JF. Nueva Gramática del Neo-liberalismo. Itinerarios teóricos, trayectorias intelectuales, claves ideológicas. E.U.: Digiprint Editores; 2008.

8. Puello-Socarrás JF, Gunturiz MA. ¿̨Social-neolibe- 
ralismo? Organismos multilaterales, crisis global y programas de transferencia monetaria condicionada. Política y Cultura [internet]. 2013 [acesso em 2017 nov 5]; 40:29-54. Disponível em: http://www.redalyc. org/articulo.oa?id=26728947003.

9. Vasconcelos KEL, Schmaler VPV. "Nem tudo que reluz é ouro": considerações sobre a (Nova) Promoção da Saúde e sua relação com o Movimento da Reforma Sanitária no Brasil. Sociedade em Debate [internet]. 2017 [acesso em 2017 jul 28]; 23(1):142-179. Disponível em: http://revistas.ucpel.tche.br/index.php/rsd/ article/view/1416/1011.

10. Lalonde M. A New Perspective on the Health of Canadians [internet]. 1974 [acesso em 2017 ago 7]. Disponível em: http://www.phac-aspc.gc.ca/ph-sp/pdf/ perspect-eng.pdf.

11. Aguiar RAT. A construção internacional do conceito de atenção primária à saúde (APS) e sua influência na emergência e consolidação do sistema único de saúde no Brasil [dissertação]. Minas Gerais: Universidade Federal de Minas Gerais; 2007. 166 p.

12. Organização Mundial da Saúde. Conferência Internacional sobre Cuidados Primários em Saúde. URSS: Declaração de Alma-Ata; 1978.

13. World Health Organization. Plan of Action Implementing the Global Strategy for Health for All. Geneva; 1982.

14. Labonte R. Health Promotion and Empowerment. Canada: Practice Frameworks; 1993.
15. Heidmann ITS, Almeida MCP, Boehs AE, et al. Promoção à Saúde: Trajetória Histórica de suas concepções. Texto e Contexto Enfermagem [internet]. 2006 [acesso em 2017 ago 10]; 15(2):352-358. Disponível em: http://www.scielo.br/pdf/tce/v15n2/a20v15n2. pdf.

16. Zioni F, Westphal MF. O Enfoque dos Determinantes Sociais de Saúde sob o ponto de vista da Teoria Social. Saúde e Sociedade [internet]. 2007 [acesso em 2017 ago 10]; 16(3):26-34. Disponível em: http:// www.scielo.br/pdf/sausoc/v16n3/04.pdf.

17. Carvalho SR. As contradições da promoção à saúde em relação à produção de sujeitos e a mudança social. Ciênc. Saúde Colet. [internet]. 2004 [acesso em 2017 jul 9]; 9(3):669-678. Disponível em: http://www. scielo.br/pdf/csc/v9n3/a13v09n3.pdf.

18. Carvalho SR. Os múltiplos sentidos da categoria "empowerment" no Projeto de Promoção da Saúde. Cad. Saúde Pública. 2004 [acesso em 2017 jul 9]; 20(4):1088-1095. Disponível em: http://www.scielo. br/pdf/csp/v20n4/24.pdf.

19. Nogueira, RP. Da Medicina Preventiva à Medicina Promotora. In: Arouca, SAS. O dilema preventivista: contribuição para a compreensão e crítica da medicina. São Paulo: Fiocruz; 2003. p. 175-182.

Aprovado em 23/03/2018

Recebido em 29/05/2018

Conflito de interesses: não houve

Suporte financeiro: inexistente 